\title{
As dimensões temáticas do termo 'informação' na Constituição Federal de 1988 da República Federativa do Brasil
}

\author{
Las dimensiones temáticas del término 'información' en la Constitución Federal de 1988 \\ de la República Federal del Brasil
}

The thematic dimensions of the term 'information' in the Federal Constitution of the Federative Republic of Brazil of 1988

\author{
João Carlos Gardini Santos, José Augusto Chaves Guimarães \\ Universidade Estadual Paulista Júlio de Mesquita Filho - UNESP, Brasil, jcgardini@gmail.com, guima@marilia.unesp.br
}

\begin{abstract}
Resumen
El término información presenta diversas acepciones dependiendo del contexto y campo en el que se inserta. En el ámbito jurídico brasileño, con la promulgación de la Constitución Federal de 1988, este término adquiere una especial importancia en el área del Derecho, ya que el acceso a la información se ha consagrado como uno de los diversos derechos fundamentales del ser humano que se contemplan en el enunciado del artículo 5 y sus incisos. De este modo, y considerando que la Constitución es la manifestación legislativa más importante de un pueblo, se busca identificar y analizar cuáles son las dimensiones temáticas que el término información presenta en la Constitución Federal de Brasil. Para esto, a través de la aplicación de análisis de contenido de Bardin (2008), se delinea como objetivo de investigación analizar cómo el término información se aborda en esta norma y cuáles son sus acepciones, a partir de las categorías previamente establecidas por Santos (2017). Finalmente, se concluye que, a pesar de la baja incidencia de este término en la Constitución Federal de Brasil, su importancia es de gran destaque debido a que está directamente relacionado con cuestiones como el derecho fundamental de acceso a la información y la difusión de información como garantía de la libertad periodística y de prensa.
\end{abstract}

Palabras clave: Información. Acceso a la información. Libertad de información. Derechos fundamentales. Análisis de contenido. Constituciones. Brasil.

\section{Introdução}

Após um longo período histórico de ditadura militar (1964-1985), foi promulgada, em 5 de outubro de 1988, a Constituição da República Federativa do Brasil, fruto de grande debate político que contou, pela primeira vez na história do país, com a participação popular, razão pela qual ela recebeu o apelido de "Constituição Cidadã".

A referida Constituição é juridicamente considerada um ato normativo promulgado (resultado de

\begin{abstract}
The term information can be used under different meanings depending on the context and the field it is inserted. More specifically in the Law field, the Brazilian Federal Constitution from 1988 gives special importance to information because it becomes a part of the fundamental rights of the citizens. This paper aims to identify and to analyze the thematic dimensions of the term information in the mentioned Federal Constitution, by means of the application of Bardin's methodology of content analysis and according to subject categories previously established by Santos (2017). It is possible to conclude that although there is a considerably low incidence of the term information, it receives a high specificity in the analyzed document, and is more directly related to the information access ant to the information freedom.
\end{abstract}

Keywords: Information. Information access. Information freedom. Fundamental rights. Content analysis. Constitutions. Brazil.

uma Assembleia Nacional Constituinte), escrito (registrado e publicado), uno (conjunto de regras organizadas e sistematizadas em um único documento), analítico (aborda todos dos assuntos considerados fundamentais pela Assembleia) e rígido (alterável somente por processos legislativos mais complexos) (Lenza, 2008; Silva, 2016).

Entre os variados temas abordados pela atual Constituição brasileira nos deparamos, logo no início, no Título II (Dos Direitos e Garantias 
Fundamentais), Capítulo I (Dos Direitos e Deveres Individuais e Coletivos), artigo $5^{\circ}$, incisos XIV, XXXIII e XXXIV, alínea b, com a questão do direito fundamental de acesso à informação. $O$ primeiro desses dispositivos constitucionais aborda o direito que toda pessoa tem de informar e de ser informada e os outros dois incisos tratam do direito de acesso à informação, de interesse particular ou geral, emanada de órgãos públicos.

Indo além, a questão da informação, na Constituição Cidadã, transcende a dimensão dos direitos fundamentais para também ser objeto de previsão em outras partes da Carta Constitucional e que abordam outros assuntos, tais como do Poder Judiciário (Seção II do Capítulo III do Título IV), dos princípios gerais da atividade econômica (Capítulo I do Título VII) e da comunicação social (Capítulo V do Título VIII).

Sendo assim, em razão das diferentes relações que o termo informação estabelece com outras temáticas no âmbito da Constituição brasileira e considerando que essa é a maior expressão legislativa de um povo, onde podemos encontrar os fatores reais de poder (Lassalle, 2000), é que urge a necessidade de analisar como o termo informação é abordado na Constituição e em quais acepções a partir das categorias previamente estabelecidas por Santos (2017), aplicando-se, para tanto, a metodologia da análise de conteúdo de Bardin (2008).

\section{A Constituição Federal brasileira de 1988}

Neste ano em que a Constituição da República Federativa do Brasil, promulgada em 5 de outubro de 1988, completa 30 anos, relembrar a sua história é reviver a memória do deputado Ulysses Guimarães (1916-1992) que, ao dar início aos trabalhos da Assembleia Nacional Constituinte de 1987, proferiu as seguintes palavras: "Senhores Constituintes, esta Assembleia reúne-se sob um mandato imperativo: o de promover a grande mudança exigida pelo nosso povo. Ecoam nesta sala as reivindicações das ruas. A nação quer mudar. A nação deve mudar. A nação vai mudar" (Oliveira, 2017).

Vale destacar que a Constituição Cidadã representou o momento máximo do país à plena democracia, ainda mais quando comparada à Constituição anterior, de 1967, posteriormente alterada pela Emenda Constitucional $\mathrm{n}^{\circ} 1 \mathrm{de}$ 1969, que fora outorgada no regime da ditadura militar. Os seguintes fatos jurídicos, amparados pela legislação, ocorridos nesse período merecem destaque: o esvaziamento dos poderes dos Estados e Municípios e a consequente concentração desses poderes no âmbito da União por meio da ampliação das competências do Presidente da República; a emissão do Ato Institucional $n^{\circ} 1$ (vigente entre os anos de 1968 e 1978) que aventou a possibilidade de suspensão, durante o seu período de vigência, dos direitos políticos dos cidadãos; e, por último, a possibilidade de cassação dos mandatos eletivos federais, estaduais e municipais.

É ainda nessa época da história brasileira que teve origem o denominado Governo de Juntas Militares, composto pelos Ministros da Marinha de Guerra, do Exército e da Aeronáutica Militar, o qual foi responsável pela constitucionalização dos atos institucionais e pela elevação do tempo do mandato presidencial para cinco anos, mantendo as eleições indiretas (Lenza, 2008).

Seguindo na história, 25 anos após o regime de exceção da ditadura militar, o Brasil vê sendo promulgada a Constituição Federal de 1988 que já em seu preâmbulo estabelece a democracia como regime de governo e fixa os valores supremos a nortearem o Estado: "[...] o exercício dos direitos sociais e individuais, a liberdade, a segurança, o bem-estar, o desenvolvimento, a igualdade e a justiça [...]" (Brasil, 1988).

O conceito de Constituição pode ser analisado sob duas perspectivas: em sentido amplo e em sentido estrito. No primeiro caso, Silva (2016, p. 37) entende que a Constituição é o "[...] simples modo de ser do Estado". Na segunda acepção, Canotilho (1994) explica que a Constituição, enquanto lei fundamental, é a origem e a organização dos elementos essenciais que norteiam a atuação do Estado.

Sobre os objetos da Constituição Federal de 1988, Novelino (2011) elenca, basicamente, os direitos e garantias fundamentais, a estrutura e organização do Estado e seus órgãos, o modo de aquisição e a forma de exercício do Poder, a defesa da Constituição, do Estado e das instituições democráticas e, finalmente, os fins socioeconômicos do Estado.

A fim de agrupar tais objetos de proteção jurídica, Lenza (2008), Novelino (2011) e Silva (2016) categorizam os dispositivos constitucionais de acordo com seus elementos definidores. Nesse sentido, a Constituição possui os elementos orgânicos, que exteriorizam as normas que regem a estrutura do Estado e dos Poderes; os elementos limitativos, que tratam, por meio de imposições aos limites de atuação do Estado, das normas definidoras dos direitos e garantias fundamentais; os elementos socioideológicos, que agregam as normas definidoras das ideologias da Constituição, como, por exemplo, as que tratam dos direitos sociais (Título II, Capítulo II) e da ordem social (Título VIII); os elementos de 
estabilização constitucional, consubstanciados nas normas de defesa da Constituição, do Estado e de suas instituições, e nas normas que tratam da solução de conflitos constitucionais (princípio da ponderação, por exemplo); e, por último, dos elementos formais de aplicabilidade, ou seja, dos dispositivos que abrangem as normas definidoras de aplicação da Constituição (preâmbulo e atos das disposições constitucionais transitórias, por exemplo).

Nunes Júnior (2018) classifica a Constituição brasileira de 1988 como formal, pois trata de tanto de matérias classicamente entendidas como constitucionais quanto de outros assuntos; escrita, uma vez que possui um documento oficial e solene que a define; dogmática, porque além de refletir um trabalho legislativo específico é reflexo de um momento histórico-social definido; promulgada, em razão de ser uma Constituição democrática, elaborada por representantes do povo, ao contrário daquelas que são outorgadas; analítica ou extensa, em razão de tratar dos mais variados assuntos; dirigente, visto que fixa metas para o Estado; e, por fim, rígida, já que possui procedimento mais rigoroso para a alteração de seu conteúdo.

Por fim, em primeiro lugar, merece destaque 0 fato do Direito Constitucional e, consequentemente, a Constituição, inserirem-se no âmbito do direito público interno e, em segundo lugar, que a sua supremacia é ratificada em razão da obediência que tanto os Poderes Executivo, Legislativo e Judiciário de todas as esferas governamentais, quanto as pessoas residentes ou que apenas estejam em trânsito pelo país encontram-se vinculados às suas normas. Além disso, destacase que todas as leis também devem obedecer às previsões constitucionais, sob pena de serem submetidas aos procedimentos de controle de constitucionalidade (Novelino, 2011).

\section{Metodologia}

A aplicação da análise de conteúdo de Bardin (2008) como metodologia de pesquisa se deve a dois motivos principais. O primeiro é porque essa metodologia permite que, a partir do corpus de análise, sejam feitas as próprias inferências. $\mathrm{O}$ segundo é porque a análise de conteúdo é a metodologia mais indicada para analisar documentos que possuem alto grau de homogeneidade quanto à forma (Guimarães; Sales, 2010), tais como as normas legais.

Dessa forma, a análise de conteúdo desenvolvese em três fases distintas: a) a pré-análise (quando são escolhidos os documentos que constituirão o corpus de pesquisa); b) a exploração do material (quando se efetiva o processo de categorização do conteúdo selecionado); e c) o tratamento dos resultados (momento no qual se realizam as inferências / interpretações do conteúdo destacado).

Sendo assim, para a realização da primeira fase, extraímos da Constituição Federal os dispositivos legais que contêm no seu texto o termo informação no singular. Optamos por analisar os trechos que contêm o termo informação nessa forma de flexão para que pudéssemos analisá-lo como um instituto em si, diferenciando-o do termo informações que constitui um coletivo mais impreciso. A segunda fase, de categorização do conteúdo, foi realizada a partir das categorias previamente estabelecidas por Santos (2017), quais sejam: a) natureza da informação; b) objeto da informação; c) objetivo da informação; d) características da informação; e e) informação como valor. A terceira fase, por fim, foi realizada de modo a apresentar a(s) inferência(s) / interpretação(ões) que cada trecho selecionado possui.

Além da análise de conteúdo, procedemos à análise de incidência do termo informação na Constituição de 1988, a fim de verificarmos quantitativamente o percentual de ocorrências e podermos comparar com os resultados obtidos na análise de conteúdo.

\section{Apresentação, análise e discussão dos resultados}

Em seu artigo $5^{\circ}$, a Constituição estabelece os direitos e garantias individuais e coletivos no âmbito dos direitos e garantias fundamentais. É justamente aqui que encontramos a primeira referência ao termo informação (Brasil, 1988):

Título II

Dos direitos e garantias fundamentais

Capítulo I

Dos direitos e deveres individuais e coletivos

Art. $5^{\circ}$ - Todos são iguais perante a lei, sem distinção de qualquer natureza, garantindo-se aos brasileiros e aos estrangeiros residentes no País a inviolabilidade do direito à vida, à liberdade, à igualdade, à segurança e à propriedade, nos termos seguintes: [...]

XIV - é assegurado a todos o acesso à informação e resguardado o sigilo da fonte, quando necessário ao exercício profissional; [...]

Tal dispositivo trata do direito fundamental (1) que todas as pessoas têm de acesso à informação. Trata-se do direito de ser informado e de informar. Com a finalidade de complementar esse mandamento, o inciso XXXIII do mesmo dispositivo constitucional estabelece que todas as pessoas possuem o direito de receber dos órgãos 
públicos informações nas quais elas têm interesse ou que sejam de interesse da coletividade, exceção feita às informações que devam ser mantidas em sigilo por motivos de segurança da sociedade e do Estado. Outro dispositivo que complementa o inciso XIV é o inciso XXXIV, alínea $\mathrm{b}$, também do artigo $5^{\circ}$. Esse dispositivo garante a todas as pessoas, independente do pagamento de taxas, a obtenção de certidões em repartições públicas com as finalidades de defesa de direitos e / ou esclarecimento de situações pessoais. Dessa forma, o direito de acesso à informação é o instrumento democrático que os cidadãos possuem para terem acesso às informações produzidas e / ou custodiadas pelo Estado (Santos; Fernández Molina; Guimarães, 2017).

Indo adiante no texto constitucional brasileiro, no âmbito da organização dos Poderes, no Capítulo que trata do Poder Judiciário, encontramos duas referências ao termo informação em dois artigos distintos, conforme podemos verificar (Brasil, 1988):

\section{Título IV}

Da Organização dos Poderes

Capítulo III

Do Poder Judiciário

Seção I

Disposições gerais

Art. 93 - Lei complementar, de iniciativa do Supremo Tribunal Federal, disporá sobre o Estatuto da Magistratura, observados os seguintes princípios:

[...] IX - todos os julgamentos dos órgãos do Poder Judiciário serão públicos, e fundamentadas todas as decisões, sob pena de nulidade, podendo a lei limitar a presença, em determinados atos, às próprias partes e a seus advogados, ou somente a estes, em casos nos quais a preservação do direito à intimidade do interessado no sigilo não prejudique o interesse público à informação; (Redação dada pela Emenda Constitucional $n^{\circ}$ 45, de 2004). [...]

Art. 100 - Os pagamentos devidos pelas Fazendas Públicas Federal, Estaduais, Distrital e Municipais, em virtude de sentença judiciária, far-se-ão exclusivamente na ordem cronológica de apresentação dos precatórios e à conta dos créditos respectivos, proibida a designação de casos ou de pessoas nas dotações orçamentárias e nos créditos adicionais abertos para este fim. (Redação dada pela Emenda Constitucional $n^{\circ} 62$, de 2009). [...]

$\S 10$ - Antes da expedição dos precatórios, o Tribunal solicitará à Fazenda Pública devedora, para resposta em até 30 (trinta) dias, sob pena de perda do direito de abatimento, informação sobre os débitos que preencham as condições estabelecidas no $\S 9^{\circ}$, para os fins nele previstos. (Incluído pela Emenda Constitucional $n^{\circ}$ 62, de 2009).
O artigo 93 elenca em seus incisos os princípios que devem nortear o Supremo Tribunal Federal na elaboração do novo Estatuto da Magistratura. Todavia, 30 anos após a promulgação da Constituição, a Suprema Corte ainda mantém-se inerte acerca da elaboração do Estatuto, razão pela qual aplica-se a Lei Complementar $n^{\circ} 35$, de 14 de março de 1979, que dispõe sobre a Lei Orgânica da Magistratura Nacional. Dentre os incisos desse artigo, destacamos como sendo de nosso interesse o IX, alterado pela Emenda Constitucional $n^{\circ} 45$ de 30 de dezembro de 2004, conhecida como Emenda da Reforma do Judiciário, que aborda o princípio da publicidade (2) que, como regra, deve reger tanto os atos processuais quanto os administrativos. À publicidade alia-se o dever de transparência que, obrigatoriamente, norteia todas atividades estatais. Destaca-se, ainda, que tanto o princípio da publicidade quanto o dever de transparência abrangem, além da questão do acesso à informação, o fato de que a linguagem utilizada para disponibilizá-la deve ser acessível e clara a todos os cidadãos.

$\mathrm{O}$ artigo 100 e seu $\S 10$, o primeiro alterado e o segundo incluído pela Emenda Constitucional $n^{\circ}$ 62 , de 9 de dezembro de 2009, abordam a questão do novo regime de pagamento dos precatórios (3). Entretanto, ambos dispositivos, de acordo com informação disponibilizada no site (4) do Supremo Tribunal Federal, foram declarados inconstitucionais pelo Plenário do Órgão quando do julgamento das ações diretas de inconstitucionalidade ${ }^{\text {os. }} 4357$ e 4425, em razão de, consoante o entendimento da maioria dos Ministros, ofenderem o princípio da isonomia. Por essa razão, maiores considerações acerca da interpretação dessas normas são desnecessárias.

Seguindo no texto constitucional brasileiro, nos deparamos com outra menção ao termo informação no Título referente à ordem econômica e financeira, a seguir transcrito.

Título VII

Da ordem econômica e financeira

Capítulo I

Dos princípios gerais da atividade econômica

Art. 181 - O atendimento de requisição de documento ou informação de natureza comercial, feita por autoridade administrativa ou judiciária estrangeira, a pessoa física ou jurídica residente ou domiciliada no País dependerá de autorização do Poder competente (Brasil, 1988).

Esse artigo apresenta o último dos princípios gerais da atividade econômica. Petter (2007) explica que a requisição de documento ou informação de natureza comercial emanada de autoridade estrangeira não possui força cogente ou, em outras palavras, não possui, por si só, força 
executória. A requisição emanada de autoridade estrangeira, para que tenha essa qualidade, dependerá de homologação de sentença pelo Superior Tribunal de Justiça e posterior execução, de acordo com o artigo 105, I, alínea i, da Constituição brasileira.

Por fim, encerrando as últimas duas menções ao termo informação na Constituição Federal, no Título que aborda a questão da ordem social, no Capítulo referente à comunicação social, encontramos os seguintes trechos:

Título VIII

Da Ordem Social

Capítulo V

Da comunicação social

Art. 220 - A manifestação do pensamento, a criação, a expressão e a informação, sob qualquer forma, processo ou veículo não sofrerão qualquer restrição, observado o disposto nesta Constituição.

$\S 1^{\circ}$ - Nenhuma lei conterá dispositivo que possa constituir embaraço à plena liberdade de informação jornalística em qualquer veículo de comunicação social, observado o disposto no art. $5^{\circ}, \mathrm{IV}, \mathrm{V}, \mathrm{X}$, XIII e XIV (Brasil, 1988).
Esse capítulo apresenta uma série de normas que protegem a imprensa, além de reafirmar e ampliar as liberdades referentes à manifestação do pensamento e à informação, também consagradas nos incisos do artigo $5^{\circ}$, conforme explicado inicialmente. Mais especificamente no caput do artigo 220 a Constituição consagra que toda e qualquer pessoa é titular do direito de disseminar informação. O parágrafo primeiro, complementando esse direito, veda a criação de leis que sejam incompatíveis com a liberdade de informação jornalística, ressalvando-se os seguintes direitos individuais que devem se harmonizar com essa liberdade: a) a proibição do anonimato (IV); b) o direito de resposta proporcional ao agravo $(\mathrm{V})$; $\mathrm{c}$ ) o direito à privacidade $(\mathrm{X})$; d) a liberdade de exercício profissional (XIII); e e) a proteção ao sigilo da fonte (XIV) (Novelino, 2011).

Já no que tange à análise de conteúdo dos dispositivos constitucionais que possuem no seu texto o termo informação, a fim de facilitar a visualização dos dados, elaboramos o quadro a seguir:

\begin{tabular}{|c|c|c|c|}
\hline Localização & Transcrição do trecho & Categoria & Interpretação \\
\hline $\begin{array}{l}\text { Título II } \\
\text { Dos direitos e garantias } \\
\text { fundamentais } \\
\text { Capítulo I } \\
\text { Dos direitos e deveres } \\
\text { individuais e coletivos }\end{array}$ & $\begin{array}{l}\text { É assegurado a todos o acesso à informação e resguardado } \\
\text { o sigilo da fonte, quando necessário ao exercício profissional }\end{array}$ & Valor & $\begin{array}{l}\text { Direito } \\
\text { fundamental } \\
\text { Direito de acesso } \\
\text { à informação }\end{array}$ \\
\hline $\begin{array}{l}\text { Título IV } \\
\text { Da Organização dos Poderes } \\
\text { Capítulo III } \\
\text { Do Poder Judiciário } \\
\text { Seção I } \\
\text { Disposições gerais }\end{array}$ & $\begin{array}{l}\text { Todos os julgamentos dos órgãos do Poder Judiciário serão } \\
\text { públicos, e fundamentadas todas as decisões, sob pena de } \\
\text { nulidade, podendo a lei limitar a presença, em determinados } \\
\text { atos, às próprias partes e a seus advogados, ou somente a } \\
\text { estes, em casos nos quais a preservação do direito à } \\
\text { intimidade do interessado no sigilo não prejudique o } \\
\text { interesse público à informação; }\end{array}$ & Natureza & $\begin{array}{l}\text { Informação de } \\
\text { interesse da } \\
\text { coletividade }\end{array}$ \\
\hline $\begin{array}{l}\text { Título IV } \\
\text { Da Organização dos Poderes } \\
\text { Capítulo III } \\
\text { Do Poder Judiciário } \\
\text { Seção I } \\
\text { Disposições gerais }\end{array}$ & $\begin{array}{l}\text { Antes da expedição dos precatórios, o Tribunal solicitará à } \\
\text { Fazenda Pública devedora, para resposta em até } 30 \text { (trinta) } \\
\text { dias, sob pena de perda do direito de abatimento, } \\
\text { informação sobre os débitos que preencham as condições } \\
\text { estabelecidas no } \S 9^{\circ} \text {, para os fins nele previstos. }\end{array}$ & Objeto & $\begin{array}{l}\text { Informação } \\
\text { sobre algo }\end{array}$ \\
\hline $\begin{array}{l}\text { Título VII } \\
\text { Da ordem econômica e } \\
\text { financeira } \\
\text { Capítulo I } \\
\text { Dos princípios gerais da } \\
\text { atividade econômica }\end{array}$ & $\begin{array}{l}\text { O atendimento de requisição de documento ou informação } \\
\text { de natureza comercial, feita por autoridade administrativa ou } \\
\text { judiciária estrangeira, a pessoa física ou jurídica residente ou } \\
\text { domiciliada no País dependerá de autorização do Poder } \\
\text { competente. }\end{array}$ & Objetivo & $\begin{array}{l}\text { Requisição e } \\
\text { prestação de } \\
\text { informações }\end{array}$ \\
\hline $\begin{array}{l}\text { Título VIII } \\
\text { Da Ordem Social } \\
\text { Capítulo V } \\
\text { Da comunicação social }\end{array}$ & $\begin{array}{l}\text { A manifestação do pensamento, a criação, a expressão e a } \\
\text { informação, sob qualquer forma, processo ou veículo não } \\
\text { sofrerão qualquer restrição, observado o disposto nesta } \\
\text { Constituição. }\end{array}$ & Valor & $\begin{array}{l}\text { Difusão da } \\
\text { informação }\end{array}$ \\
\hline $\begin{array}{l}\text { Título VIII } \\
\text { Da Ordem Social } \\
\text { Capítulo V } \\
\text { Da comunicação social }\end{array}$ & $\begin{array}{l}\text { Nenhuma lei conterá dispositivo que possa constituir } \\
\text { embaraço à plena liberdade de informação jornalística em } \\
\text { qualquer veículo de comunicação social, observado o } \\
\text { disposto no art. } 5^{\circ}, \text { IV }, \mathrm{V}, \mathrm{X}, \mathrm{XIII} \text { e XIV. }\end{array}$ & Natureza & $\begin{array}{l}\text { Informação } \\
\text { jornalística }\end{array}$ \\
\hline
\end{tabular}

Quadro 1. Análise de conteúdo 
Das cinco categorias extraídas da pesquisa de Santos (2017) e que são passíveis de aplicação nesse trabalho, quatro foram atribuídas aos seis trechos selecionados da Constituição: natureza da informação (duas incidências $\cong 33,33 \%$ do total), objeto da informação (uma incidência $\cong$ $16,66 \%$ do total), objetivo da informação (uma incidência $\cong 16,66 \%$ do total) e informação como valor (duas incidências $\cong 33,33 \%$ do total).

Explicando as categorias utilizadas na análise de conteúdo, sobre a natureza da informação, consideramos como sendo as características essenciais que são atribuídas ao termo. Nesse sentido, no primeiro caso, a característica essencial atribuída à informação é ser de interesse da coletividade; já no segundo, a característica essencial atribuída ao termo é simplesmente o fato de tratar-se de informação jornalística.

Sobre o objeto da informação, entendemos o objeto como sendo o resultado de uma ação. Portanto, a ação de solicitar informação sobre algo gerará o seu objeto que é a informação sobre algo solicitado. Já em relação ao objetivo da informação, entendemos que objetivo é aquilo que se pretende obter. Logo, o objetivo de requisição da informação e seu atendimento gerará a sua obtenção.

Por fim, no que tange à informação como valor, entendemos como sendo "[...] a máxima do uso efetivo feito pelo usuário e, que não pode ser confundida com outras tentativas de mensurar a informação a partir de seu custo de produção ou manutenção do pessoal que colabora" (Almeida; Varvakis, 2005, p. 56). Assim, no primeiro caso o uso é o próprio direito de acesso à informação que pode ser exercido a qualquer momento. No segundo, o uso atribuído ao termo informação é a sua difusão.

Em relação à análise de incidência do termo informação realizada na Constituição Federal, excluídos os atos das disposições constitucionais transitórias e pautando-se no texto atualizado até a Emenda Constitucional $\mathrm{n}^{\circ}$ 99, de 14 de dezembro de 2017, observamos um conjunto de duzentos e cinquenta artigos, divididos em nove títulos, cada qual com suas respectivas divisões em capítulos, seções e subseções. Desse total de dispositivos, o termo informação possui seis incidências em cinco artigos o que representa, na relação entre o total de artigos presentes atualmente na Constituição por artigos que apresentam incidência do termo informação, o percentual de apenas $2 \%$ (dois por cento) do total.

\section{Considerações finais}

Ainda que, atualmente, a incidência do termo informação na Constituição seja somente de $2 \%$ (dois por cento) do total de artigos vigentes, podemos destacar que o termo informação, objeto de análise do presente estudo, é, efetivamente, um instituto jurídico. Podemos citar as seguintes constatações que validam essa afirmação:

a) $O$ direito de acesso à informação é um direito individual e fundamental razão pela qual, além de possuir as características já citadas, é cláusula pétrea (artigo 60, $\S 4^{\circ}$, IV, Constituição Federal), ou seja, é um dispositivo constitucional que não pode ser alterado por nenhuma lei utilizada no processo legislativo, nem mesmo por Proposta de Emenda à Constituição (PEC);

b) A existência das democracias modernas pressupõe, além da efetivação do direito de acesso à informação, a livre manifestação, criação e expressão do pensamento, acrescidas à plena liberdade de informação jornalística e dos demais meios de comunicação, fato esse, também previsto expressamente na Constituição Federal brasileira;

c) Acrescenta-se à essas constatações as considerações do estudo realizado por Santos (2017), o qual observou que a taxa de incidência do termo informação foi inferior nos acórdãos proferidos pelo Supremo Tribunal Federal a partir da promulgação da Lei de Acesso à Informação (Lei $n^{\circ} 12.527$, de 18 de novembro de 2011) porque a partir do momento em que o Estado conceitua a informação, além de reconhece-la como um instituto do Direito, o termo passa a ser utilizado de forma mais precisa e não mais como sinônimo de dado, conhecimento, notícia ou mensagem.

Como se pode observar, a importância atribuída pela Constituição Federal do Brasil à informação é bastante relevante e específica em razão de esse termo estar diretamente relacionado a questões como o direito fundamental de acesso à informação e a difusão de informação como garantia da liberdade jornalística e da imprensa.

A análise realizada na Constituição Brasileira vigente, tal como exposto neste artigo, confirma as conclusões anteriores de Guimarães e Santos (2016), Santos e Guimarães (2016) e Santos (2017) oriundas de pesquisa na jurisprudência brasileira, confirmando-se em ambos os casos na jurisprudência e na legislação -, o status da informação como efetivamente um instituto jurídico no direito brasileiro, vale dizer, um conceito específico que possui peculiaridades próprias e que, portanto, deve ser tratado de forma especial, como é o caso do casamento, do furto, da licitação e tantos outros, além da reiteração da 
necessidade de sua previsão específica em tesauros jurídicos.

\section{Notas}

(1) Expressão cunhada por Antonio Enrique Pérez Luño em 1770 na França durante o momento histórico, político e cultural que precedeu a Declaração Universal dos Direitos do Homem e do Cidadão, de 1789. São características dos direitos fundamentais: universalidade, inalienabilidade, imprescritibilidade, historicidade, irrenunciabilidade e a relatividade quando encontrarem limitações em outros direitos fundamentais (Novelino, 2011).

(2) Destaca-se que a própria Constituição Federal apresenta algumas exceções ao princípio da publicidade, tais como o sigilo da fonte, contraposto ao acesso à informação, quando necessário ao exercício profissional (artigo $5^{\circ}$, XIV) ou o sigilo das informações quando necessário à segurança da sociedade e do Estado em contraposição ao acesso às informações, de interesse particular ou coletivo, produzidas e/ou custodiadas pelo Estado (artigo $5^{\circ}$, XXXIII) (Brasil, 1988).

(3) Silva (2007, p. 1073) explica que precatório é "[...] a carta se sentença remetida pelo juiz da causa ao Presidente do Tribunal para que este requisite ao Poder Público, mediante previsão na lei orçamentária anual, o pagamento de quantia certa para satisfazer obrigação decorrente de condenação das pessoas políticas, suas autarquias e fundações".

(4) https://bit.ly/2pbNfVS (2018-06-21).

\section{Referências}

Almeida, Carlos Cândido de; Varvakis, Gregório (2005). Valor e Ciência da Informação: serviços de informação baseados na gestão de operações de serviço. // Informação \& Sociedade: Estudos. 15:1 (2005) 49-74.

Bardin, Laurence (2008). Análise de Conteúdo. Lisboa: Edições 70, 2008.

Brasil (1988). Constituição Federal (1988). Constituição da República Federativa do Brasil. Promulgada em 5 out. 1988. Brasília, DF, Senado Federal, 5 out. 1988. http://www.planalto.gov.br/ccivil_03/constituicao/constituicaocompilado.htm (2018-02-08).

Canotilho, José Joaquim Gomes (1994). Constituição dirigente e vinculação do legislador: contributo para a compreensão das normas constitucionais programáticas. Coimbra: Coimbra, 1994
Guimarães, José Augusto Chaves; Sales, Rodrigo de (2010). Análise Documental: concepções do universo acadêmico brasileiro em Ciência da Informação. DataGramaZero Revista de Ciência da Informação. 11:1 (2010) 1-17.

Guimarães, José Augusto Chaves; Santos, João Carlos Gardini (2016). A ementa jurisprudencial como resumo informativo em um domínio especializado: aspectos estruturais. // Brazilian Journal of Information Studies: Research Trends. 10:3 (2016) 32-43.

Lassalle, Ferdinand (2000). A essência da Constituição. $5^{\text {a }}$ ed. Rio de Janeiro: Lumen Juris, 2000.

Lenza, Pedro (2008). Direito Constitucional esquematizado. $12^{\mathrm{a}}$ ed. São Paulo: Saraiva, 2008.

Novelino, Marcelo (2011). Direito Constitucional. $5^{\text {a }}$ ed. São Paulo: Método, 2011.

Nunes Júnior, Flávio Martins Alves (2018). Curso de Direito Constitucional. $2^{\mathrm{a}}$ ed. São Paulo: Revista dos Tribunais, 2018.

Oliveira, Guilherme (2017). 30 anos da Constituição Cidadã. // Agência Senado (2017). https://www12.senado.leg.br/ noticias/infograficos/2017/10/30-anos-da-constituicao-cidada (2018-02-04).

Petter, Lafayete Josué (2007). Direito Econômico. $2^{\mathrm{a}}$ ed. Porto Alegre: Verbo Jurídico, 2007.

Santos, João Carlos Gardini (2017). As dimensões temáticas da informação na jurisprudência brasileira: uma análise a partir dos acórdãos do Supremo Tribunal Federal. 2017. Trabalho de conclusão de curso.

Santos, João Carlos Gardini; Fernández Molina, Juan Carlos; Guimarães, José Augusto Chaves (2017). Direito de acesso à informação: uma análise a partir das realidades espanhola e brasileira. // Informação \& Sociedade: Estudos. 27:2 (2017) 49-62.

Santos, João Carlos Gardini; Guimarães, José Augusto Chaves (2016). As dimensões temáticas da informação na jurisprudência brasileira: uma análise a partir dos acórdãos do Supremo Tribunal Federal do Brasil. // Neto, Luísa; Ribeiro, Fernanda (orgs.) (2016). Direito e Informação na Sociedade em Rede: atas. Faculdade de Direito e Faculdade de Letras da Universidade do Porto: Porto, 2016. 408-418.

Silva, De Plácido e (2007). Vocabulário Jurídico. 27. ed. Rio de Janeiro: Forense, 2007.

Silva, José Afonso da (2016). Curso de Direito Constitucional. $40^{a}$ ed. São Paulo: Saraiva, 2016

Enviado: 2018-04-13. Segunda versión: 2018-06-05. Aceptado: 2018-06-22. 
